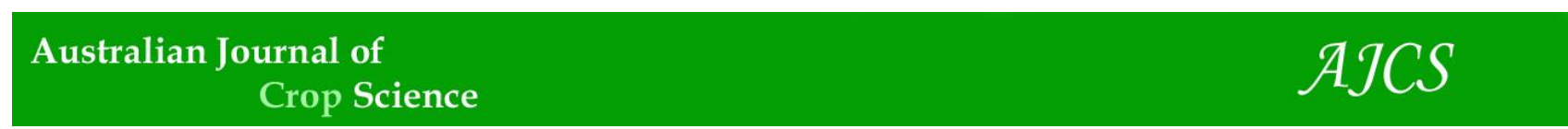

AJCS 11(06):757-767 (2017)

ISSN:1835-2707

doi: 10.21475/ajcs.17.11.06.p446

\title{
Variation in expression of $S u b 1$ gene confers differential response to submergence tolerance in rice (Oryza sativa L.)
}

\author{
A.S.M Masuduzzaman ${ }^{1}$, Md. Maksudul Haque ${ }^{2 *}$, A.K.M Shamsuddin ${ }^{3}$, M.A Salam ${ }^{1}$, Md. Shahjahan \\ Kabir $^{4}$, Ardashir Kharabian-Masouleh ${ }^{5}$, Md. Enamul Haque ${ }^{6}$, Md. Ansar Ali
}

${ }^{1}$ Plant Breeding Division, Bangladesh Rice Research Institute, Gazipur, Bangladesh

${ }^{2}$ Golden Rice Project, Plant Breeding Division, Bangladesh Rice research Institute (BRRI), Gazipur-1701, Bangladesh

${ }^{3}$ Department of Genetics and Plant Breeding, Bangladesh Agricultural University, Mymensingh, Bangladesh

${ }^{4}$ Administration and Common Service, Bangladesh Rice Research Institute, Gazipur, Bangladesh

${ }^{5}$ Queensland Alliance for Agriculture and Food Innovation (QAAFI), The University of Queensland, St Lucia, QLD, Australia

${ }^{6}$ Biotechnology Division, Bangladesh Rice Research Institute, Gazipur, Bangladesh

${ }^{7}$ Director Research, Bangladesh Rice Research Institute, Gazipur, Bangladesh

*Corresponding author: maksudulhq@gmail.com

\begin{abstract}
A cluster of three ethylene response factor (ERF) like genes at the Sub1 locus has been identified from rice variety FR13A that confers tolerance to submergence for about 14 days. Restriction digestion-based haplotype variations among 11 rice accessions were analyzed to generate polymorphisms at SublC and SublA loci. Considering different combinations of SNPs (haplotype), four haplotypes: A1C1, A1C2, A2C2 and A0C2 were detected. Further, using semi-quantitative RT-PCR - Sub1A and Sub1C transcripts in different haplotypes were interpreted in respect with stem elongation and survival for understanding mechanism of submergence tolerance. Expression variations in Subl genes in relation with duration of submergence, haplotype diversity and an interaction of loci were found. Differential expression of SublA and SublC affected the stem elongation and survival of different haplotypes differentially. In tolerant varieties (A1C1 haplotype, IR40931), the highest expressed gene was Sub1A; while expression of Sub1C was lower. Over-expression of SublA gene in tolerant varieties, suppressed the stem elongation under submergence, which improved the level of submergence tolerance. In susceptible cultivar (Fulkari), the highest-expressed gene was SublC, while the SublA was not expressed which showed higher susceptibility. In moderately tolerant varieties (Kottamali), both SublA and Sub1C gene transcripts were up-regulated by submergence and higher level of both SublA and Sub1C genes transcripts. The varieties in A2C2 haplotype showed moderate level of tolerance without the SublA1 allele and a distinct novel mechanism favored the expression of both the Sub1A and Sub1C alleles that confer higher tolerance under complete submergence.
\end{abstract}

Keywords: SublA, Haplotypes, Gene expression, distinct mechanism, submergence tolerance, Rice.

Abbreviations: ERF_Ethylene Response Factor; MAP_Marker-assisted gene pyramiding; CAPS_cleaved amplified polymorphic site; ELPs_Expression level polymorphisms; DEPC_Diethyl Pyrocarbonate; RT-PCR_Reverse transcription polymerase chain reaction; PCR_Polymerase chain reaction; SNP_Single-nucleotide Polymorphism; QTL_Quantitative trait locus; RNA_Ribonucleic acid; mRNA_messenger RNA; DNA_Deoxyribonucleic acid; cDNA_Complementary DNA; d_Days.

\section{Introduction}

The variety FR13A has been found to be relatively more submergence tolerant. This is a farmer's variety choice from Orissa, India (Mackill, 1986). IRRI has confirmed that FR13A can survive about 14 days of complete submergence. Traditional rice varieties, FR13A can thrive in regions affected by flash floods where modern varieties could not survive (Mackill et al., 2012; Mohanty et al., 2000; Xu et al., 2006). Flood Resistant, FR13A can restrict its elongation growth, economizing its carbohydrate reserves to enable new leaves upon de-submergence (Fukao et al., 2011). Thus, the physiological response of rice plants to flooding is mainly of two types: (a) submergence tolerance, by which tolerant varieties can survive under complete submergence (b) rapid elongation ability of leaves and internodes, by which the varieties avoid the complete submergence, genotypes (Chen et al., 2011; Luo et al., 2011, Sarkar and Bhattacharjee 2012; Vergara et al., 2014, Mohanty et al., 2000). A negative correlation between survival and elongation growth was found, when tolerance is inherited from FR13A (Yamada, 1959; Sasaki et al., 2000a,b; Jackson et al., 1987; Sardana, 1997). Under flash flooding, limited stem elongation growth was found to be associated with a cultivar's ability to survive.

Developing high-yielding, submergence tolerant rice varieties are needed (Mackill et al. 2012; Ismail 2013; Septiningsih et al. 2013; Singh et al. 2013). A cluster of three related ethylene response factor (ERF)-like genes at the Subl locus, has been identified (Xu et al., 2006). Two markers (close to Subl) were converted to the cleaved amplified 
polymorphic site (CAPS) markers, through digesting amplified products with respective restriction enzymes and clear tolerant specific SublAl and SublCl alleles were found in tolerant accessions. Intolerance was found to be associated with poor submergence induced SublA2 (and Sub1C2) or complete absence of Sub1A. The discovery of Sub1A gene facilitated its introgression to high yielding varieties (BaileySerres et al., 2010; Collard et al., 2013; Mackill et al., 2012). New submergence tolerance rice varieties with Sub1A gene might be able to resist floods. Although FR13A has been successfully used as tolerance source, additional sources are needed. Pyramiding several genes into the same background is the most effective breeding strategy (Mackill, 2003).

Information provided by SNPs is most useful, when gene based haplotypes of a region are being examined (Rafalski, 2002). A linear arrangement of alleles (i.e., nucleotides) at different SNPs on a single chromosome, or part of a chromosome, is called a haplotype (Judson et al., 2002). Haplotype diversity has the advantage to find new source of gene (McCartney et al., 2004). Haplotype data associated with phenotypic combination are also useful for grouping of genotypes based on presence and absence of a particular allele. Xu et al. (2006) analyzed haplotype diversity of rice and found identical submergence tolerant haplotypes. Bai et al. (2003) and McCartney et al. (2004) used previously identified markers that flank target locus. Detecting novel QTLs via haplotype based comparison has advantage over expensive QTL mapping (McCartney et al., 2004). Thus, haplotype analysis and haplotype based gene expression is useful to examine potential polymorphism of the Subl locus.

RT-PCR (Reverse Transcriptase Polymerase Chain Reaction) analysis is applied to detect differential expression of a specific gene. Reverse Transcriptase synthesizes the complementary copies of messenger RNAs of the single stranded RNA. Semi-quantitative RT-PCR is a highly sensitive method for the detection of rare transcripts (Carding and Bottomly, 1992). The number of copies of produced RNA is called the expression level of the gene (Xu, 2005). Gene is "on" when the cell makes mRNA, and "off" when the cell does not make it. Differences in gene expression, termed as expression level polymorphisms (ELPs) (Doerge, 2002) have been found to be associated with flowering-time control (Johanson et al., 2000; Caicedo et al., 2004) and pathogen resistance (Grant et al., 1995; Gassmana et al., 1999) in Arabidopsis.

In addition, specific sequence of nucleotides constitutes a gene that has specific phenotype and expression. SNPs can change the property of that gene, if they occur in coding or regulatory regions (Pungliya, 2001). Furthermore, haplotypebased expression analysis is also more informative than analysis based on individual SNPs (Rafalski, 2002). Guangming et al. (2006) identified different haplotypes at a leucine-rich repeat receptor kinase gene cluster of rice accessions. Gene-expression differences contributing to phenotypic variation are useful to understand the genetic basis of a complex trait (Schadt et al., 2003), and to understand evolutionary forces (Wilson et al., 1974; Wray et al., 2003) and mechanism of stress tolerance. Qu and Xu (2006) described a cluster analysis of gene expression data aiming at classifying genes into groups based on the similarity of their expression.

Epistasis can be defined as interaction between two alleles at different loci. However, biological epistasis results from physical interactions between bio-molecules (e.g. DNA, RNA, proteins, enzymes, etc.). Complex traits are caused by multiple genes and study suggests that gene $\times$ gene interaction plays an important role (Clark and Wang, 1997;
Storey et al., 2005). Many biological processes have been reported to be affected by epistasis, including aluminum tolerance in rice (Wu et al. 2000).

The transcriptional interactions affect the transcription rate of another gene or set of genes. Xu et al. (2006) and Fukao et al. (2006) detected the submergence tolerance mechanisms in tolerant and intolerant rice varieties and they described that SublA inhibits ethylene production and underwater elongation. Expression of SublA gene also suppresses a nearby ethylene-responsive paralogous gene (SublC). Submergence tolerant landrace (FR13A) and its derivative lines have been extensively exploited in mechanistic studies, because of their higher level of tolerance.

Recent study of Masuduzzaman et al. (2016) identified few more tolerant genotypes, those are distinct from 'FR13A' (non-Subl type of tolerant, Madabaru, Kottamali). Efforts are needed to investigate strengths of transcriptional interactions of alleles related to tolerance.

In view of the above introduction, the present study was undertaken (1) to investigate the relationship between level of SublA and Sub1C transcripts in different haplotypes under different submergence stress and (2) to detect the effect of different patterns of expression of SublA and SublC on elongation growth to understand the basis of tolerance in different accessions.

\section{Results and discussion}

\section{Patterns of haplotype frequencies and distributions}

In this study, SublA and SublC allele specific haplotype based analysis was performed among 11 rice varieties. Different combinations of two genes at the Subl locus (called haplotype) in 11 varieties are shown in Table 4. Each haplotype is indicated with two digits: the first digit " $\mathrm{A}$ " is for the Gns2 pattern and the second digit " $\mathrm{C}$ " for the ERF173. For example, A1C1 indicates that this haplotype has Sub1A1 allele, and Sub1C1 allele. A0C2 indicated that this haplotype has Sub1A0 (absence of Sub1A) and Sub1C2 alleles. In this SNP study, three patterns at Sub1A locus: Sub1A0 (null allele), Sub1A1 (does not cut), and Sub1A2 (one SNP) were found and two patterns generated at Sub1C locus: Sub1C1 and Sub1C2. Considering different combinations of SNPs (called haplotype), four haplotypes: $\mathrm{A} 1 \mathrm{C} 1, \mathrm{~A} 1 \mathrm{C} 2, \mathrm{~A} 2 \mathrm{C} 2$ and $\mathrm{A} 0 \mathrm{C} 2$ (Table 1) were detected among 11 genotypes. The present investigation has demonstrated the usefulness of haplotype technique, as a reliable typing tool for the differentiation of submergence tolerant varieties and for analysis of haplotype variation.

Gene-based haplotype analysis has increased power over single-allele studies. It has been emphasized by many researchers (Rafalski, 2002; Johnson et al., 2001; Stephens, 2001; Ching et al., 2002).

\section{Expression of Sub1A and Sub1C influenced by submergence}

Fig 1 and 2, demonstrated SublA and SublC transcripts and elongation growth of selected varieties from different haplotypes under $3 \mathrm{~d}$ and $7 \mathrm{~d}$ of submergence. Most of rice varieties die when completely immersed in water for more than 7 d (Bailey-Serres et al., 2010; Fukao \& Xiong 2013; Ismail et al. 2013; Singh et al. 2014). A significant variability of SublA and SublC transcripts was found among two submergence level. At 3d, SublA was expressed at relatively 
Table 1. Tolerance level, A/C ratio and elongation of different haplotypes at Seven days of submergence.

\begin{tabular}{|c|c|c|c|c|c|c|c|}
\hline \multirow[t]{2}{*}{ Haplotype } & \multirow[t]{2}{*}{ Varieties } & \multirow[t]{2}{*}{ Elongation } & \multirow[t]{2}{*}{ Survival } & \multicolumn{2}{|c|}{ Expression value } & \multirow[t]{2}{*}{$\mathrm{A} / \mathrm{C}$ ratio } & \multirow[t]{2}{*}{ Remarks } \\
\hline & & & & SublA & SublC & & \\
\hline \multirow[t]{3}{*}{ A1C1 } & IR40931 & $40 \%(\mathrm{~L})$ & $95 \%$ & 87 & 56 & 1.55 & Tolerant \\
\hline & Gopalbhog & $100 \%(\mathrm{H})$ & $30 \%$ & 40 & 94 & 0.43 & MS \\
\hline & Motorsail & $75 \%(\mathrm{M})$ & $66 \%$ & 120 & 117 & 1.02 & MT \\
\hline A1C2 & Mach ranga & $76 \%(\mathrm{M})$ & $86 \%$ & 119 & 111 & 1.07 & MT \\
\hline \multirow[t]{2}{*}{ A2C 2} & Kottamali & $66 \%(\mathrm{M})$ & $78 \%$ & 119 & 117 & 1.02 & MT \\
\hline & IR42 & $93 \%(\mathrm{H})$ & $12 \%$ & 75 & 114 & 0.64 & $\mathrm{~S}$ \\
\hline $\mathrm{A} 0 \mathrm{C} 2$ & Chamara & $137 \%(\mathrm{H})$ & $5 \%$ & 20 & 94 & 0.02 & $\mathrm{~S}$ \\
\hline
\end{tabular}

Each haplotype is indicated with two digits: the first digit "A" is for the Gns2 pattern and the second digit "C" for the ERF173. A1C1 haplotype has Sub1 A1 allele, and Sub1C1 allele. A0C2 haplotype has Sub1 A0 (absence of Sub1A) and Sub1C2 alleles. The data are representative of three independent experiments. $L=$ low, $M=$ medium and $\mathrm{H}=$ high. $\mathrm{MT}=$ moderate tolerant, $\mathrm{MS}=$ moderately susceptible, and $\mathrm{S}=$ susceptible

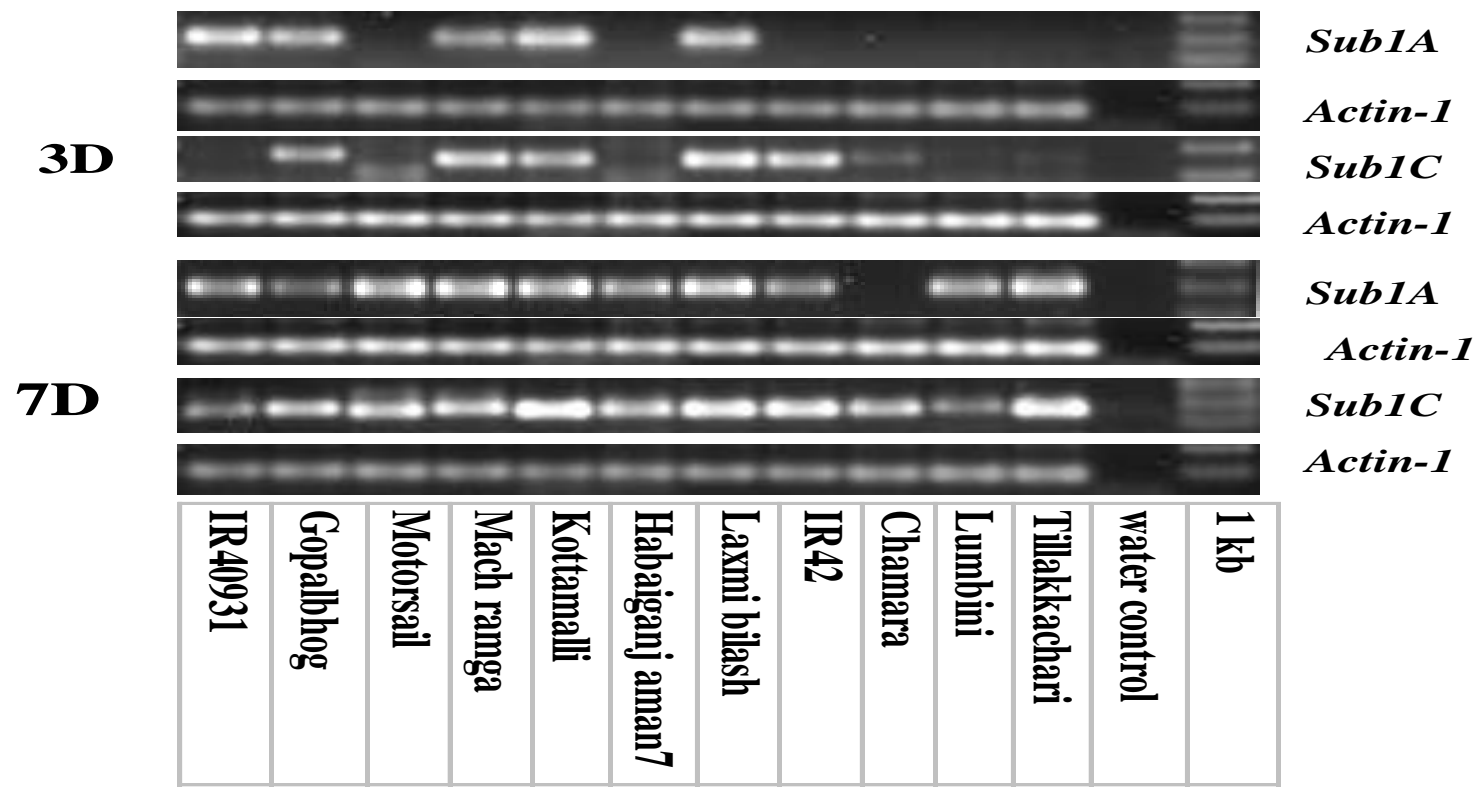

Fig 1. Expression variation of SublA andSublC in response to submergence of 3d and 7d. The band intensity of SublA and SublC, was normalized to actin-1, as loading control.

Table 2. Correlation between SublA and SublC expression values with traits related to submergence tolerance.

\begin{tabular}{ll}
\hline Traits & Correlations coefficients (r) \\
\hline Elongation\% vs. Survival \% & $-0.89^{* * *}$ \\
Sub1C expression vs. Elongation \% & $0.56^{*}$ \\
Sub1A expression vs. Elongation \% & $-0.75^{* *}$ \\
Sub1A expression vs. Sub1C expression & $-0.57^{*}$ \\
A C ratio vs. Elongation. & $-0.88^{* *}$ \\
SublA expression vs. Survival\% & $0.77^{* *}$ \\
SublC expression vs. Survival\% & $-0.37^{*}$ \\
Average of 3 replications of 11 samples used for analysis. ${ }^{*},{ }^{* *}$ and ${ }^{* * *}$ indicated significant at $5 \%, 1 \%$ and $0.1 \%$ levels of probability, respectively.
\end{tabular}

Table 3. A/C ratio, elongation percentage (\%) and survival percentage (\%) of T, MT and S varieties.

\begin{tabular}{lccc}
\hline Varieties & A/C ratio & Elongation \% & Survival \% \\
\hline IR40931( T) & 1.55 & 40 & 95 \\
Kottamali (MT) & 1.02 & 66 & 78 \\
IR42 ( S) & 0.64 & 93 & 12 \\
\hline
\end{tabular}

\footnotetext{
$\mathrm{A} / \mathrm{C}$ indicates the ratio of gene expression values of Sub1A and Sub1C. T= Tolerant, MT= Moderately tolerant, $\mathrm{S}=$ Susceptible.
} 


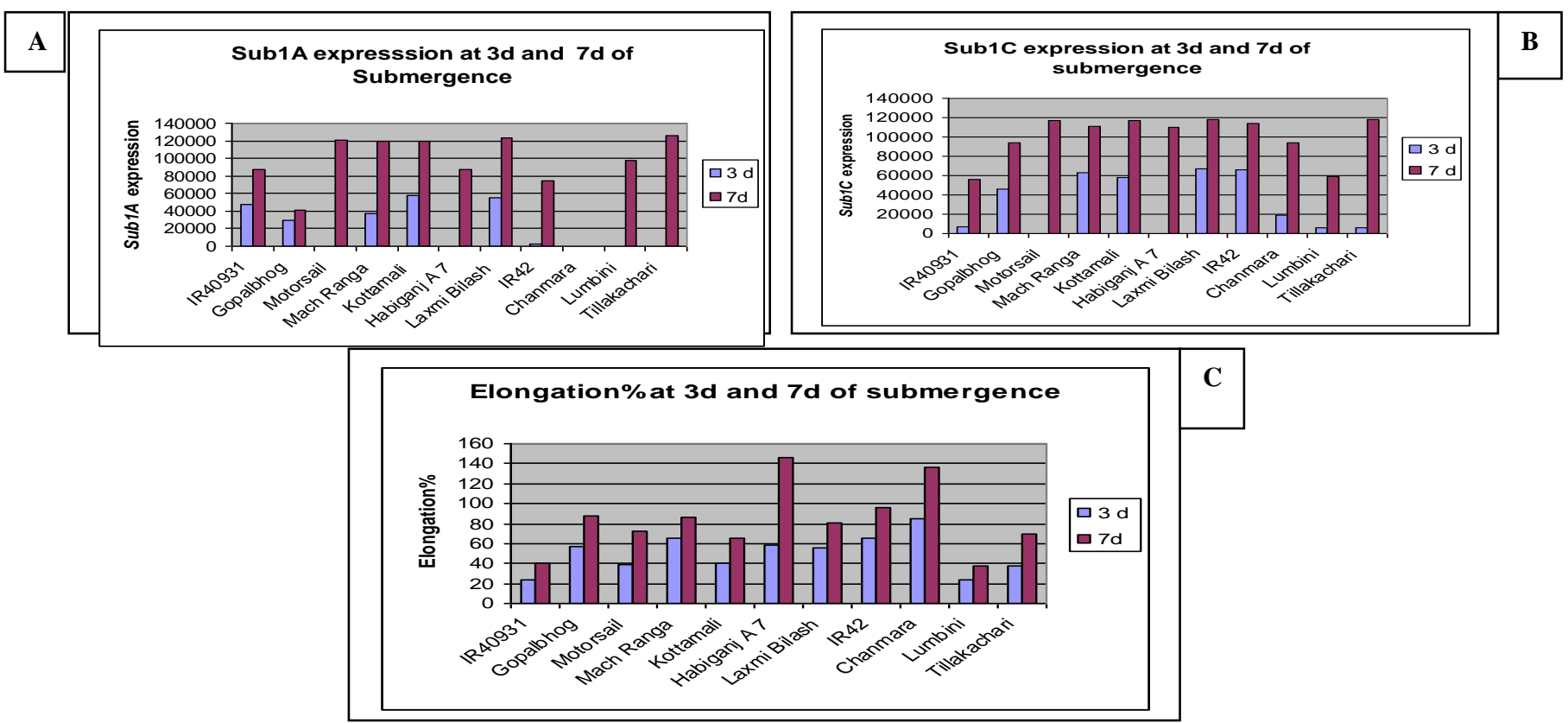

Fig 2. Allelic expression variation of SublA, SublC and elongation (\% in response to submergence stress of $3 \mathrm{~d}$ and $7 \mathrm{~d}$.A) the bar graph shows an increase of SublA transcripts at 7d, compared with 3d. B) The bar graph shows an increase of SublC transcripts at $7 \mathrm{~d}$, compared with $3 \mathrm{~d}$ C) Increased elongation $\%$ can be seen in the $7 \mathrm{~d}$ submergence stressed seedlings, compared with $3 \mathrm{~d}$.
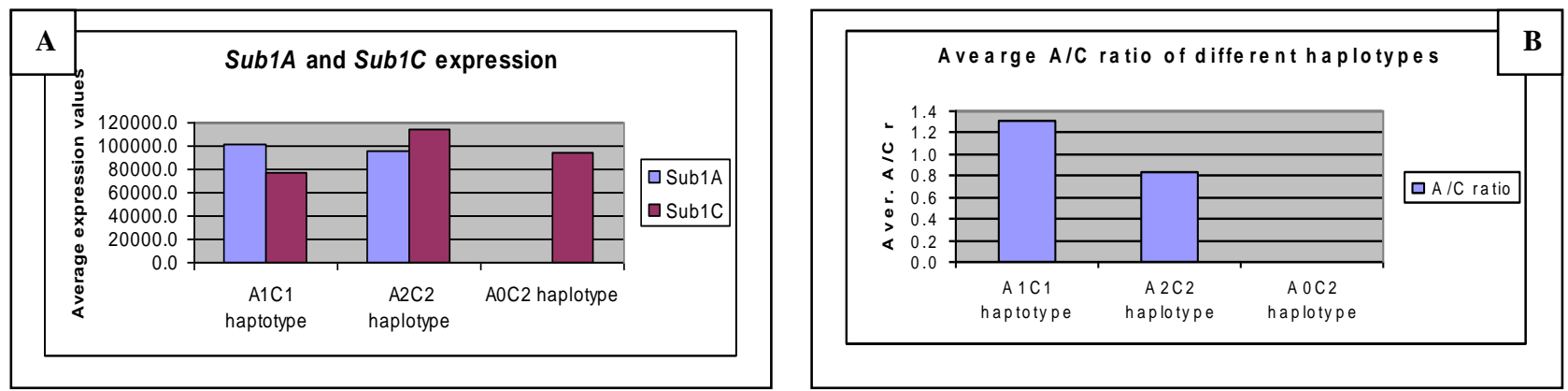

Fig 3. The bar graphs representing, SublA and SublC transcripts and A/C ratio in different haplotypes. (A) Average SublA and SublC transcripts in different haplotypes at 7d of submergence. (B) Average A/C ratios of different haplotypes.

Table 4. List of varieties for expression studies from different haplotypes.

\begin{tabular}{|c|c|c|c|c|}
\hline \multirow[t]{2}{*}{ SL } & \multirow{2}{*}{ Varieties } & \multicolumn{2}{|c|}{ Genotype } & \multirow{2}{*}{ Phenotype } \\
\hline & & SublA & SublC & \\
\hline 1 & IR40931 & SublAl & SublCl & $\mathrm{T}$ \\
\hline 2 & Gopalbhog & SublAl & SublC1 & MS \\
\hline 3 & Motorsail & SublAl & SublC1 & MT \\
\hline 4 & Mach Ranga & SublAl & SublCl & MT \\
\hline 5 & Kottamalli & SublA2 & SublC2 & MT \\
\hline 6 & HabiganjAman 7 & SublA2 & SublC2 & $\mathrm{S}$ \\
\hline 7 & LaxmiBilash & SublA2 & SublC2 & MT \\
\hline 8 & IR42 & SublA2 & SublC2 & $\mathrm{S}$ \\
\hline 9 & Chamara & SublA2 & Sublc2 & S \\
\hline 10 & Lumbini & SublAl & SublCl & $\mathrm{T}$ \\
\hline 11 & Tillakachari & Subl A2 & SublC2 & MT \\
\hline
\end{tabular}

Table 5. Nucleotide sequence of gene specific primers and thermo cycling conditions for RT-PCR.

\begin{tabular}{|c|c|c|c|c|}
\hline Primers & Sequence of primers & AnnealingTemp $\left({ }^{\circ} \mathrm{C}\right)$ & No ofcycles & PCR product size (bp) \\
\hline SublA & F: $5^{\prime}$-GAT GTG TGG AGG AGA AGT GA-3' & 54 & 33 & 203 \\
\hline SublC & $\begin{array}{l}\text { R: 5'-TGT TTT GGT GGA TCG ATG GG-3 } \\
\text { F: 5'-AAC GCC AAG ACC AAC TTC C-3' } \\
\text { R: 5'-AGG AGG CTG TCC ATC AGG T-3' }\end{array}$ & 53 & 34 & 173 \\
\hline Actin-1 & F: 5'-ACA GGT ATT GTG TTG GAC TC-3' & 53 & 35 & 118 \\
\hline
\end{tabular}




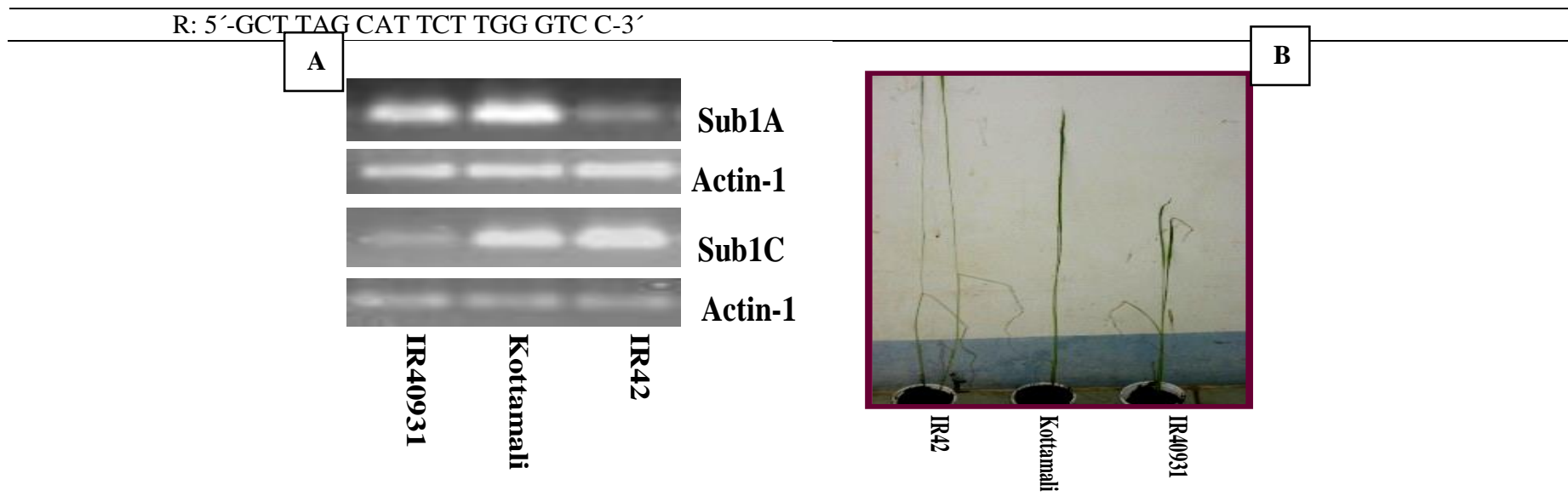

Fig 4. Differential expression of SublA and SublC influencing elongation growth. (A) Expression of SublA and SublC in T (IR40931), MT (Kottamali) and S (IR42) varieties. (B) Phenotypes of respective varieties under 12 days of submergence.

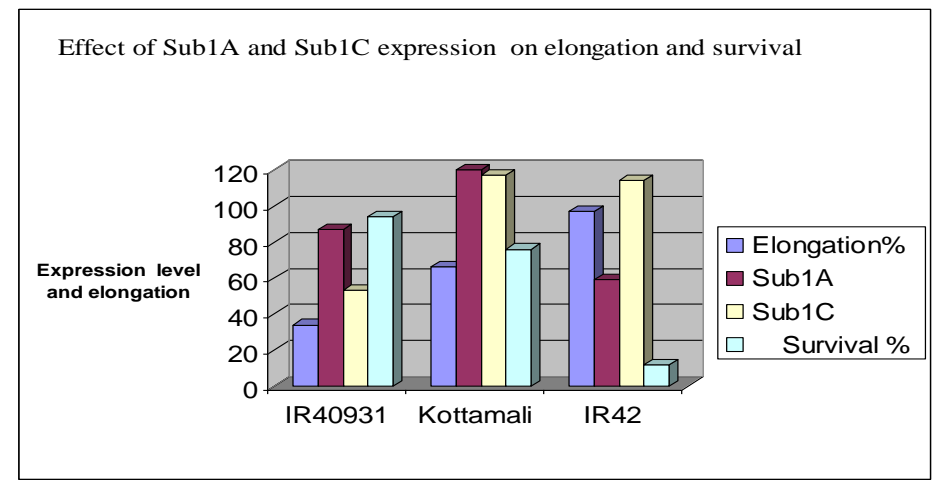

Fig 5. Comparing expression of SublA and SublC and elongation and survival in T, MT and S varieties. Each long, medium long and small bars indicated high, medium and low level of expression values A) In IR40931, higher expression of SublA reduced the SublC and depressed elongation B) In Kottamali, novel mechanism favored the expression of both the alleles and medium elongation. C) In IR42, suppression of Sub1A - favoured expression of strong elongation and up regulation of Sub1C.

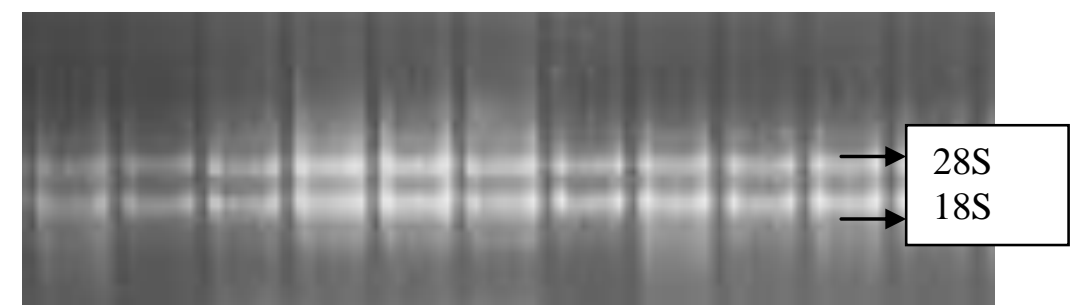

Fig 6. The intact RNA was indicated by clearly visible $18 \mathrm{~S}$ and $28 \mathrm{~S}$ rRNA bands.

lower level in eight varieties. The expression level was nil in 3 varieties (Chamara, Motorsail, and Habiganj aman). However, increased transcripts of SublA and increased elongation growth at $7 \mathrm{~d}$ were found compared with $3 \mathrm{~d}$. Similarly, the level of SublC transcripts and elongation growth were relatively lower at $3 \mathrm{~d}$ of submergence, but SublC mRNA was highly accumulated at $7 \mathrm{~d}$ stress. These results clearly indicated that increased duration of submergence led to abundance of SublA and SublC transcripts. Submergence stimulates ethylene accumulation andinternodes elongation (Banga et al., 1996; Kende et al., 1998). Findings of Xu et al. (2006) and Fukao et al. (2006) demonstrated that the Subl region haplotype determines ethyleneand GA-mediated metabolic and developmental responses to submergence through differential expression of SublA and SublC genes. In our experiment, submergence stress of $7 \mathrm{~d}$ led to a significant increase in elongation and increased transcription of ethylene-responsive SublA and
Sub1C genes compared with $3 \mathrm{~d}$ of submergence. The increased duration of submergence ultimately increased inter node elongation of shoot, although the increases of elongation were not equal for all the varieties. We concluded that different patterns of expression of SublA and SublC affected the elongation growth and survival differentially. Several studies have also focused importance of Subl gene for reduced elongation under full submergence conditions (Baxter et al., 2014; Fukao et al., 2011; Liu et al., 2015; Yang and Hong 2015). Thus, development of tolerant varieties with SublA gene has been found highly effective (Singh et al., 2009; 2013; Iftekharuddaula et al., 2011; Dar et al., 2013). Although elongation plays a central role in adaptive responses to submergence, excessive elongation might cause negative responses to the survival of plants. The increased duration of submergence enhances elongation and ultimately ethylene enhances the enzymatic degradation of chlorophyll and the consumption of carbohydrate reserves. The difference 
in response to two submergence treatments indicated the importance of placing transcript profiling results in the context of physiological responses. After seven days of submergence, the expression of SublA and SublC transcripts was clear. Both of these genes were expressed in all varieties. The identification of the Subl locus genes exhibiting large expression differences under submergence might provide a novel insight into the functional basis of submergence tolerance in rice. Increased expression of genes following salt and heat stresses have been reported in rice and Arabidopsis (Larkindale and Vierling., 2008; Rizhsky et al., 2004; Busch et al., 2005; Schramm et al., 2006; Kilian et al., 2007).

\section{Gene expression ratios to predict tolerant phenotype}

The expression level of SublA gene relative to the expression level of the $S u b 1 C$ gene in a single sample was presented and the ability of pair-wise expression ratios (A/C) to predict tolerant level of varieties was tested compared with tolerant control (IR40931). Table 1 showed haplotype based association of A/C ratio with the phenotype. In IR40931, SublA was up-regulated and SublC was down-regulated at $7 \mathrm{~d}$ of submergence. This variety with its higher A/C ratio (> 1) and higher survival (95\%) was predicted as highly tolerant. In IR42, expression level of SublC was higher than SublA (lower expression) and; thus, the $\mathrm{A} / \mathrm{C}$ ratio was much lower than 1 (12\% survival), which predicted as intolerant. In Kottamali and Motorsail, the expression level of both SublA and SublC was higher and thus $\mathrm{A} / \mathrm{C}$ near 1 (65-80\% survival) was predicted as moderately tolerant. The expression ratio might be useful for diagnosis of tolerant level in different varieties. Yap et al. (2004) suggested that pair-wise gene expression ratio can identify reliable results for differentiation of the samples.

\section{Haplotype-specific regulation of transcripts}

Expression of Subl locus genes was determined in different varieties and they were selected from different haplotype classes. The average value of SublA and SublC transcripts and $\mathrm{A} / \mathrm{C}$ ratio of three haplotypes were shown in Fig 3 . Attempts to amplify Sub1A failed in Chamara (A0C2 haplotype) that has a null allele at the SublA locus. On average, A1C1 haplotype had relatively more SublA transcripts, while less Sub1C (higher A/C ratio) than $\mathrm{A} 0 \mathrm{C} 2 / \mathrm{A} 2 \mathrm{C} 2$ haplotypes, indicating major role of higher SublA1 (suppression of elongation) and lower Sub1C1 transcripts for higher tolerance. Intolerant cultivars (IR42, Habigang Aman7) of A2C2 haplotype had weak induction of SublA gene and the SublC allele was also up-regulated by submergence. These varieties seemed to have less capacity to suppress elongation growth. It seems that single nucleotide polymorphisms at SublA allele could be responsible for its differential expression (SNPs that alter protein function). These findings agreed with the findings of $\mathrm{Xu}$ et al. (2006) and Fukao et al. (2006). According to their results SublA2 allele of intolerant $\mathrm{A} 2 \mathrm{C} 2$ haplotypes had a single nucleotide change as compared to the SublAl allele.

Analysis of transcripts of moderately tolerant varieties (Motorsailand and Kottamali) indicated that both SublA and SublC transcripts were up-regulated by submergence, which was distinct from transcripts of reference varieties. Other factors might alter the regulation of the $S u b 1$ genes in these varieties. Further interpretation of expression data are needed for understanding the source of expression differences in Motorsail and Kottamali varieties.
The transcript levels of two ERF genes at the Subl locus were evaluated in different haplotypes (43) varieties having slow, medium and strong elongation) under $7 \mathrm{~d}$ of submergence. A correlation analysis was used to investigate the pleiotropic effects of traits related to tolerance (Table 2). Elongation showed positive correlation with SublC (r=0.56) and negative correlation with $\operatorname{SublA}(\mathrm{r}=-0.75)$, and survival $\%(\mathrm{r}=-0.89)$ as well negative correlation with $\mathrm{A} / \mathrm{C}$ ratio $(\mathrm{r}=-$ 0.88). This association suggested that higher SublA transcripts had higher potential to maintain slower elongation and lesser Sub1C transcripts, as well more $\mathrm{A} / \mathrm{C}$ ratio and higher survival \% in tolerant varieties. Similarly, intolerant varieties with lower $\mathrm{A} / \mathrm{C}$ ratio showed strong elongating types, having lower survival \% and lower portion of SublA transcripts after submergence. This also indicated that high elongation and high SublC transcripts were damaging, whereas the more elongation, the lower SublA transcripts and higher SublC were found. Negative correlation of SublA and SublC transcripts $(\mathrm{r}=-0.57)$ indicated that expression of SublA possibly suppressed SublC. But, this inverse relationship was not very strong in moderately tolerant varieties Kottamali and Motorsail, as these varieties had high level of both SublA and SublC transcripts, in presence of moderate level of elongation. It seems that SublA did not suppress $S u b 1 C$ in MT varieties and involvement different type of tolerance mechanism.

\section{Mechanism of submergence tolerance}

Fig 4 and 5, compare the differential expression of two alleles (SublA and SublC) and their effect on elongation and survival in 3 groups of varieties. The strength of interaction (either antagonistic or synergistic) effect of SublA on elongation and SublC is important for understanding of submergence tolerance mechanism in different varieties. Furthermore, tolerance level increases or decreases depend on presence or absence of SublA allele and their differential interaction with $S u b 1 C$. The A/C ratio or tolerance level can be increased, through an increase expression rate of beneficial SublA and a decrease rate of SublC.

\section{Tolerant A1C1 haplotype}

The changes in $\mathrm{A} / \mathrm{C}$ ratio and effects on elongation and survival are shown in Table 3. Over expression of beneficial SublA favoured to down-regulation of the Sub1C (Fig 5) and maintained higher $\mathrm{A} / \mathrm{C}$ ratio (strong correlation). High $\mathrm{A} / \mathrm{C}$ ratio also indicated antagonistic relationship between $S u b 1 A$ and SublC (enhanced SublA and repressed Sub1C). A genetic interaction between $S u b l A$ and SublC may be relevant, because antagonistic relationships between ERFs have been recognized (McGrath et al., 2005; Fujimoto, et al., 2000). Quantitative traits are influenced by multiple genes and much evidence from model organisms suggests that genexgene interaction plays an important role for expression of a trait (Clark and Wang, 1997; Storey et al., 2005). High $\mathrm{A} / \mathrm{C}$ ratio showed exclusively negative skewness to lower the elongation (40\%) and; thus, suppressed elongation improved the survival (95\%). The presence of less deleterious allele for slow elongation probability resulted in beneficial contribution for over expression of SublA that further reduced the elongation. Similar results were found by Xu et al. (2006) in which SUB1 gene introgressed into cultivars and showed higher tolerance and same mechanisms of tolerance in rice (Iftekharuddaula et al., 2011; Mackill et al., 2012; Neeraja et al., 2007; Septiningsih et al., 2009, 2013, 2015; Singh et al., 
2009). Gene-based markers were used to improve tolerance to submergence (Septiningsih et al., 2015).

\section{Susceptible A0C2 and A2C2 haplotypes}

These haplotypes shared either less beneficial SublA2 or deleterious SublAO (absence of SublA). Absence of SublA allele in A0C2 haplotype or presence of intolerant specific Sub1A2 (has less capacity for suppression of elongation) in A2C2 haplotype led to the epigenetic up-regulation of SublC expression and pronounced more elongation (Fig 5). Due to poor expression of Sub1A, A/C ratio <1 was maintained in susceptible varieties. Excessive elongation (93\% in IR42) becomes lethal. It enhanced leaf chlorosis, and enzymatic degradation of chlorophyll. Strong elongation is considered as a dominant trait (Masuduzzaman et al., 1999), and might respond towards high susceptibility. Similar results were found by Xu et al. (2006).

\section{Moderately tolerant A1C1 and A2C2 haplotypes}

There was up-regulation of both SublA and SublC transcripts at the same levels and an $\mathrm{A} / \mathrm{C}$ almost equal to 1 was maintained (Table 3). It seemed that due to synergistic effects, the presence of SublA transcripts have the potential to enhance the SublC transcripts (enhancing both alleles). An increase of both the transcripts would be a welcome situation to reflect a balance between SublA and SublC transcripts in shoot that indicated moderate level of elongation $(66 \%$ in Kottamali) and moderate level of tolerance. The balanced transcript rates of Sub1A and Sub1C allowed plants to reach fitness equilibrium. Moderate level of elongation was not lethal for survival. The limited levels of elongation in Kottamali caused less leaf chlorosis and showed $78 \%$ survival upon de-submergence.

Sub1A2 allele is intolerant specific and varieties in $\mathrm{A} 2 \mathrm{C} 2$ haplotype were found as intolerant (11). However, Kottamali and Tillakkachari in $\mathrm{A} 2 \mathrm{C} 2$ haplotype showed moderate level of elongation and moderate submergence tolerance. Respective mechanisms to limit the high elongation exist in these varieties. Novel mechanisms might influence the up regulation of SublC allele in the presence of SublA transcripts that probably modified the tolerance level. It is likely that expression of less lethal medium elongation background of Kottamali favored the novel mechanism, which possibly led to an increase of SublA and SublC transcripts. These results suggested that major allele for elongation of Kottamali should be a particularly good candidate for the source of novel genes for submergence tolerance. These results are distinct from several studies in rice for submergence tolerance (Xu et al., 2006, Singh et al., 2009; Jantaboon et al., 2011; Bailey-Serres et al., 2012; Dar et al., 2013).

\section{Materials and methods}

\section{Studies of haplotype}

A total of 11 rice varieties (Table 4) were chosen for haplotype analysis. In the present study, two CAPS markers, GnS2 and ERF173 were closely linked to Sub1A and Sub1C alleles (at Sub1 region), respectively. They were used as diagnostic markers. Genomic DNA was extracted from each rice genotypes, using single plant leaf tissues. PCR reaction and the PCR condition were performed using standard protocol.
Restriction digestion of PCR fragments was assayed with enzyme $C a c 8 \mathrm{I}$ and $A l u \mathrm{I}$ to generate polymorphisms at Sub1C and Sub1A loci, respectively, according to manufacturer's instructions (BioLabs). The separated bands were visualized under UV light and photographs were taken. Molecular weight for cut and un-cut bands was measured using Alfa Imager software.

\section{Plant materials and submergence treatment}

Eleven varieties from different haplotypes (Masuduzzaman et al., 2016), differing in tolerance (Table 4) were examined. For assaying SublA and SublC expression, 4 sets of seedlings of 11 varieties were raised in separate plastic trays, containing grinded soils. Except the control tray, other 2 trays with 14 days old seedlings were submerged completely in water tank for $3 \mathrm{~d}$ and $7 \mathrm{~d}$. After submergence for $3 \mathrm{~d}$, one tray was taken out of water tank. The shoot tissues were cut in to sections (5 to $10 \mathrm{~mm}$ ) and were taken in to $2 \mathrm{ml}$ tubes, quickly. The samples were frozen immediately in liquid nitrogen and stored at $-80^{\circ} \mathrm{C}$. Similarly, after $7 \mathrm{~d}$ of submergence, desubmerged shoots and the corresponding non-submerged controls were also sampled for analysis. All leaves of each variety were harvested at $3 \mathrm{PM}$ on the day of treatment specified and special care was taken not to thaw the samples.

\section{Measuring elongation and submergence score}

Before collecting leaves of submerged plants of each treatment, plant height was measured. To observe the response of increased elongation growth on gene expression, elongation was calculated, as compared with initial plant height (non-submerged control) of each variety. The trays were kept in screen house for recovery of seedlings. The data of seedling height and percent of survival were taken from five randomly selected seedling before submergence, after each treatments $(0,3$ and 7 days of submergence) and after the 7 th day of recovery.

\section{TRI reagent (RNA Isolation Reagent) based protocol for RNA extraction}

Total RNA from shoot tissue samples was extracted following TRI Reagent (Sigma Aldrich, USA) based protocol. Frozen tissue sample (approxo. 80-100 mg) was taken in a prechilled mortar. It was then powdered by grinding in mortar and frequently or periodically liquid nitrogen was added into the mortar to prevent thawing. While pulverizing the tissue into a powder, the tissue should was kept completely frozen to isolate intact total RNA. Finally,

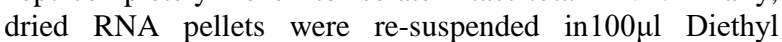
Pyrocarbonate (DEPC) treated double distilled water and pipette rapidity until pellet was completely re-dissolved.

\section{Quality check of RNA}

RNA samples and amplification reactions were assembled on ice and extra care (gloved hands, dust free pipette's and working area) was taken to save the samples from contamination and degradation by RNase. RNase-free tips and plastic tubes and solutions (that have been treated with DEPC to inactivate RNase) were used. RNA integrity was assessed by comparing the relative intensities of the $28 \mathrm{~S}$ and $18 \mathrm{~S}$ rRNA bands (Fig 6) in 1.5\% agarose gel electrophoresis, stained with SYBR safe. Total RNA concentration and purity (260/280 ratio) were also measured in duplicate by the NanoDrop (NanoDrop Technologies). Only the RNA 
samples having a 260/280 ratio between 1.8 and 2.0 were used. Subsequently the samples were diluted with nucleasefree water to a concentration of $100 \mathrm{ng} / \mu \mathrm{l}$. The diluted $10 \mu \mathrm{l}$ of each RNA sample was treated with the RNase-free DNase for $30 \mathrm{~min}$ at $37^{\circ} \mathrm{C}$ (Promega, Madison, WI) to remove traces of contaminating DNA, followed by treating with RNase inhibitor for 10 minute at $65^{\circ} \mathrm{C}$ in $0.5 \mathrm{ml}$ tubes in a thermal cycler, according to the manufacturer's instructions (Promega). Then, concentration of purified RNA was measured again in duplicate by the NanoDrop. Finally samples were diluted to a conc. of $33.3 \mathrm{ng} / \mu \mathrm{l}$ and the RNA stock solutions were stored at $-20^{\circ} \mathrm{C}$.

\section{Semi-quantitative RT-PCR for cDNA synthesis}

For the first strand cDNA synthesis, semi-quantitative RTPCR was performed in a single tube, using one step RT-PCR kit (Invitrogen). $100 \mathrm{ng}(3 \mu \mathrm{l})$ of high-quality total RNA was used as a template. The RT reactions were performed in a 25 $\mu 1$ reaction mixture consist of $22 \mu 1$ of the RT-PCR reagent mixture and $3 \mu 1$ of total RNA (100ng). For one reaction, the RT-PCR reagent mixture contained: RNase-free water $6.75 \mu 1,12.5 \mu 1$ of $1 \mathrm{X}$ one-step RT-PCR buffer (Invitrogen, Carlsbad CA), $1 \mu$ l gene specific forward and reverse gene specific primers mixture, DSMO $1.25 \mu \mathrm{l}$ and $0.5 \mu \mathrm{l}$ of onestep RT-PCR/ Platinum Taq mix (Invitrogen, Carlsbad CA), and over layered with 1 drop of nuclease-free mineral oil (Sigma), according to the manufacturer's instructions. After reaction assembly, the tables were transferred into a thermal cycler (G-Strom) (pre-heated to the desired cDNA synthesis temperature of $50^{\circ} \mathrm{C}$ ) and immediately the RT-PCR amplification program was started with 1 cycle of reverse transcription at $50^{\circ} \mathrm{C}$ for $30 \mathrm{~min}$ and then PCR condition consists of: initial denaturation for $5 \mathrm{~min}$ at $94^{\circ} \mathrm{C}$, followed by 30 to 33 cycles of $95^{\circ} \mathrm{C}$ for $15 \mathrm{~s}$, annealing at $53-55^{\circ} \mathrm{C}$ for $30 \mathrm{~s}$ and extension at $72^{\circ} \mathrm{C}$ for 1 minutes, and a final extension step at $72^{\circ} \mathrm{C}$ for $8 \mathrm{~min}$. In thermal cycler, cycling conditions was optimized for each primers pair to ensure amplification products did not reach saturation (Table 5).

To control contamination from previous sample, a control reaction without RNA template was set up. For more reliable results, three replicates were performed for each sample. The mRNA levels were determined for SublA and SublC and for one housekeeping gene: actin-1. The transcript levels were compared across multiple samples, based on band intensity of amplification products relative to internal control (actin1) that was expressed at a relative constant level among all samples. The major purpose of normalization is to correct for non-specific variation, such as differences in RNA quantity and quality, which can affect efficiencies of the RT and PCR reactions.

\section{Preparation of $1.5 \%$ agarose gel}

To quantify the gene expression of SublA and SublC and Actin-1, the RNA samples were run on $1.5 \%$ agarose gel electrophoresis. For preparing $300 \mathrm{ml} 1.5 \%$ agarose gel, $4.5 \mathrm{~g}$ agarose (BMA products; U.S.A.) was taken in $300 \mathrm{ml} \mathrm{1X}$ TBE buffer on a conical flux. It was then placed in microwave oven and was heated until solution turned transparent. The flask was swirled and the solution was cooled to $60^{\circ} \mathrm{C}$ for 20 minutes. For assembling the gel united, the gel deck was placed on a level surface (checking the bubble level) and two casting dams (wedges) were sealed by apply gentle pressure in the sealing surfaces against the sides of the gel deck. Pre-cool, agarose gel was then poured smoothly into the gel casting deck and air bubbles were removed with a pipit. The combs were inserted into the desired position and allowed the gel to solidify at room temperature for about half an hour. Once the gel got solidified, it was transferred to electrophoresis tank, containing $1 \mathrm{X}$ TBE gel running buffer. The level of buffer was kept at least $4-5 \mathrm{~mm}$ above the gel. Then the comb was removed from the solidified gel.

\section{Agarose gel electrophoresis of PCR products}

$10 \mu \mathrm{l}$ of each PCR product was mixed with $3 \mu \mathrm{l}$ of $5 \mathrm{X}$ gel loading dye. $10 \mu \mathrm{l}$ of prepared mixture was then loaded in wells of $1.5 \%$ agarose gel and the electrophoresis was carried out in submarine gel electrophoresis at constant voltage $80 \mathrm{~V}$ for 1.5 hours in $1 \mathrm{X}$ TBE, until the bromophenol blue (the faster-migrating dye) was migrated as far as $2 / 3$ of the gel length. The gel was stained in CYBR safe strain $(30 \mu 1$ CYBR safe in $300 \mathrm{ml}$ water) for 30 minutes. The amplified products were then visualized under UV light and documented by gel documentation system. Amplification specificity was validated by melt-curve analysis at the end of each PCR experiment. PCR efficiency (90-105\%) was verified by the method of Schmittgen \& Livak (2008).

\section{Data analysis}

Molecular size for cut and un-cut bands was determined using Alfa Imager version 5.5 software program. SNP based association was analyzed to determine allelic variants (presence or absence of SNP) and to differentiate tolerant and intolerant specific Sub1A and sub1C alleles. Effective number of haplotypes (particular patterns of sequential SNPs) was determined. Management of raw data and graphical presentation were done using Microsoft Excel 2003 programme. The haplotype variations and relationships between haplotypes was analyzed using simple comparison. The specific band intensity for $S u b A$ and $S u b C$ with respect to a housekeeping gene (actin-1) was compared from semiquantative RT-PCR data at two time points ( 3 and 7 days of submergence). Relative transcript abundance was calculated using the comparative cycle threshold method (Livak \& Schmittgen 2001). The intensity of each band of SublA, and SublC was measured, using an IS-1000 Digital Imaging System (Alpha Innotech) and quantities using Flurochem version 2.0 software (Alpha EaseFC analysis software). The normalized intensity values were detected in comparison with the lowest negative control ' 0 '. The expression values for the three replicates were averaged to find the expression values. The simple ratio of the expression (Rosenwald et al., 2003) of SublAand SublC genes in a single sample was used for grouping the varieties. Genes with $\mathrm{A} / \mathrm{C}$ ratio of $>1$ were considered as up-regulated $S u b 1 A$ and down regulated SublC, while genes with a mean $\mathrm{A} / \mathrm{C}$ ratio of $<1$ considered as down-regulated SublA and up-regulated Sub1C. A/C ratio almost 1 indicated up-regulation of both the genes. Bar graphs represented the relative band intensity of SublA and SublC at $3 \mathrm{~d}$ and $7 \mathrm{~d}$ of submergence. Expression values and elongation means of genotypes were compared. Gene expression values were treated as quantitative trait (Gibson and Weir, 2005) to find out interactions between alleles (Phillips, 1998 and Brem et al., 2005). If expression of two interacting alleles increase in a positive skewness (higher value), synergistic epistasis has occurred. If one allele increase in the positive skewness and other one decrease, then antagonistic epistasis has occurred. Finally, we investigate the relationship between the average survival and 
elongation of varieties due to differential expression of SublA and SublC.

\section{Conclusion}

Expression variation in Subl genes was found in relation to duration of submergence, haplotype diversity (null allele, SNP) and interactions of loci. On average, A1C1 haplotype (IR40931) had relatively more Sub1A transcripts, and less SublC than A2C2. In tolerant varieties, higher SublA transcripts, lower elongation, lower $S u b l C$ transcripts and higher survival were found. Over-expression of SublA suppressed the elongation which improved the level of tolerance. The varieties Madabaru, and Kottamali (A2C2) showed moderate level of tolerance without the Sublal allele. These two varieties are the potential source of novel submergence tolerance genes. In Kottamali (A2C2), Sub1A and $S u b 1 C$ acted synergistically, in which expression levels of both SublA and SublC were higher. This is a welcome situation to modify the tolerance level over other varieties in A2C2 haplotype. In A1C1 haplotype (IR4093), higher Sub1A expression, lower SublC transcripts, lower elongation and higher survival were found. In tolerant varieties, the expression of SublA reduced the elongation. The suppressed elongation improved the level of survival. A novel mechanism favored the expression of both the alleles that caused limited leaf chlorosis and moderate level of elongation. These results suggested that the alleles for elongation of Kottamali should be a particularly good candidate for the source of novel genes for submergence tolerance.

\section{References}

Bailey-Serres J, Lee SC, Brinton E (2012) Waterproofing crops: effective flooding survival strategies. Plant Physiolo. 160:1698-1709.

Bailey-Serres J, Fukao T, Ronald P, Ismail AM, Heuer S and Mackill DJ (2010) Submergence tolerant rice: Sub1's journey from landrace to modern cultivar. Rice. 3: 138147.

Bai GH, Guo PG, Kolb FL (2003) Genetic relationships among head blight resistant cultivars of wheat assessed on the basis of molecular markers. Crop Sci. 43: 498-507.

Banga M, Slaa EJ, Blom CW, Voesenek LA (1996) Ethylene biosynthesis and accumulation under drained and submerged conditions. Plant Physiol. 112: 229-237.

Brem RB and Kruglyak L (2005) The landscape of genetic complexity across 5,700 gene expression traits in yeast. Proc Natl Acad Sci. 102: 1572-1577.

Busch W, Wunderlich M, Schöffl F (2005) Identification of novel heat shock factor-dependent genes and biochemical pathways in Arabidopsis thaliana. Plant J. 41: 1-14.

Caicedo AL, Stinchcombe JR, Olsen KM, Schmitt J, Purugganan MD (2004) Epistatic interaction between ArabidopsisFRI and FLC flowering time genes generates a latitudinal cline in a life history trait. Proc Natl Acad Sci. 101: 15670-15675.

Carding S, Lu D, Bottomly KA (1992) A polymerase chain reaction assay for the detection and quantification of cytokine gene expression in small number of cells. J Immunol Methods. 151: 277-287.

Chen X, Visser EJW, de Kroon H, Pierik R, Voesenek LACJ, Huber H (2011) Fitness consequences of natural variation in flooding induced shoot elongation in Rumex palustris. New Phytolo. 190: 409-420.
Ching A, Caldwell KS, Jung M, Dolan M, Smith OS, Tingey S, Morgante M, Rafalski AJ (2002) SNP frequency, haplotype structure and linkage disequilibrium in elite maize inbred lines. BMC Genet. 3: 19.

Clark AG and Wang L (1997) Molecular population genetics of Drosophila immune system genes. Genetics.147: 713724.

Collard BCY, Septiningsih EM, Das SR, Carandang J, Pamplona AM, Sanchez DL, Kato Y, Ye G, Reddy JN, Singh US, Iftekharuddaula KM, Venuprasad R, Vera-Cruz CN, Mackill DJ, Ismail AM (2013) Developing new floodtolerant varieties at the International Rice Research Institute (IRRI). Sabrao J Breed Genetics. 45: 42-56.

Dar MH, Janvry AD, Emerick K, Raitzer D, Sadoulet E (2013) Flood tolerant rice reduces yield variability and raises expected yield, differentially benefitting socially disadvantaged groups. Sci Rep. 3:1-8.

Doerge RW (2002) Mapping and analysis of quantitative trait loci in experimental populations. Nat Rev Genet. 3: 43-52.

Fujimoto SY, Ohta M, Usui A, Shinshi H. Ohme-Takagi M (2000) Arabidopsis ethylene-responsive element binding factors act as transcriptional activators or repressors of GCC box-mediated gene expression. Plant Cell.12: 393404

Fukao T, Xiong L (2013) Genetic mechanisms conferring adaptation to submergence and drought in rice: simple or complex? Curr Opin Plant Biol. 16: 196-204.

Fukao T, Yeung E, Bailey-Serres J (2011) The submergence tolerance regulator SUB1A mediates crosstalk between submergence and drought tolerance in rice. Plant Cell. 23(1):412-427

Fukao T, Xu K, Ronald PC, Bailey-Serres J (2006) A variable cluster of ethylene response factor-like genes regulates metabolic and developmental acclimation responses to submergence in rice. The Plant Cell. 18: 2021-2034.

Gassmann W, Hinsch ME, Staskawicz BJ (1999) The Arabidopsis RPS4 bacterial-resistance gene is a member of the TIR-NBS-LRR family of disease-resistance genes. Plant J. 20: 265-277.

Gibson G, Weir B (2005) The quantitative genetics of transcription. Trends Genetics. 21(11):616-623.

Grant MR, Godiard L, Straube E, Ashfield T, Lewald J, Sattler A, Innes ARW and Dangl JL (1995) Structure of the Arabidopsis Rpml gene enabling dual-specificity disease resistance. Science. 269: 843-846.

Guangming H, Luo X, Tian F, Li K, Zhu Z, Su W, Qian X, Fu Y, Wang X, Sun C and Yang J (2006) Haplotype variation in structure and expression of a gene cluster associated with a quantitative trait locus for improved yield in rice. Genome Res. 16: 618-626.

Iftekharuddaula KM, Newaz MA, Salam MA, Ahmed HU, Mahbub MAA, Septiningsih EM, Collard BCY, Sanchez, DL, Pamplona AM, Mackill DJ (2011) Rapid and highprecision marker assisted backcrossing to introgress the SUB1 QTL into BR11, the rainfed lowland rice mega variety of Bangladesh. Euphytica 178: 83-97.

Ismail AM, Singh US, Singh S, Dar MH, Mackill DJ (2013) The contribution of submergence-tolerant (Sub1) rice varieties to food security in floodprone rainfed lowland areas in Asia. Field Crops Res. 152: 83-93.

Jackson MB, Waters I, Setter TL, Greenway H (1987) Injury to rice plants caused by complete submergence: a contribution of ethylene. J Exp Bot. 38: 1826-1838.

Jantaboon J, Siangliwa M, Im-markb S, Jamboonsria W, Vanavichitc A, Toojindaa T (2011) Ideotype breeding for 
submergence tolerance and cooking quality by markerassisted selection in rice. Field Crops Res. 123:206-213.

Johnson GC, Esposito L, Barratt BJ, Smith AN, Heward J, Genova GD, Ueda H, Cordell HJ, Eaves IA, Dudbridge F, Twells RC, Payne F, Hughes W, Nutland S, Stevens H, Carr P, Tuomilehto-Wolf E, Tuomilehto J, Gough SC, Clayton DG, Todd JA (2001) Haplotype tagging for the identification of common disease genes. Nat Genet. 29: 233-237.

Judson R, Salisbury B, Schneider J, Windemuth A and Stephens JC (2002) How many SNPs does a genome-wide haplotype map require? Pharmacogenomics. 3: 379-391

Larkindale J and Vierling E (2008) Core genome responses involved in acclimation to high temperature. Plant Physiol.146:748-761.

Livak KJ and Schmittgen TD (2001) Analysis of relative gene expression datausing real-time quantitative PCR and the 2- $\Delta \Delta \mathrm{CT}$ method. Methods $25,402-408$.

Luo FL, Nagal KA, Scharr H, Zeng B, Schurr U, Matsubara $S$ (2011) Recovery dynamics of growth, photosynthesis and carbohydrate accumulation after de-submergence: a comparison between two wetland plants showing escape and quiescence strategies. Annals Bot. 107:49-63.

Kilian J, Whitehead D, Horak J, Wanke D, Weinl S, Batistic O, D'Angelo C, Bornberg-Bauer E, Kudla J, Harter K (2007) The AtGenExpress global stress expression data set: protocols, evaluation and model data analysis of UV-B light, drought and cold stress responses. Plant J. 50: 347363.

Kende H, Knaap E, Cho HT (1998) Deepwater rice: A model plant to study stem elongation. Plant Physiol. 118: 11051110.

Masuduzzaman ASM, Haque M, Ahmed MME, Mohapatra CK (2016) SSR marker-based genetic diversity analysis of tidal and flood prone areas in rice (Oryza sativa L.). J Biotechnol Biomater 6: 241. doi:10.4172/2155952X.1000241

Masuduzzaman ASM, Rasul MG, Bos I (1999) Genetics of seedling length and plant height in rice. Bangladesh J Plant Breed Genet. 12(1\&2):13-19.

Mackill DJ, Ismail AM, Singh US, Labios RV, Paris TR (2012) Development and rapid adoption of submergencetolerant (Sub1) rice varieties. Adv Agron. 115: 303-356.

Mackill DJ, Ismail AM, Singh US, Labios RV, Paris TR (2012) Development and rapid adoption of submergencetolerant (Sub1) rice varieties. Adv Agron. 115: 303-356.

Mackill DJ (2003) What molecular tools are available for selection for drought tolerance. In: Manual, Breeding rice for drought-prone environments. 4.4: 55-57.

Mackill DJ (1986) Rainfed lowland rice improvement in South and Southeast Asia: results of a survey. In 'Progress in Rainfed Lowland Rice. International Rice Research Institute: Los Baños, Philippines. pp. 115-144

McCartney CA, Somers DJ, Fedak G, Cao W (2004) Haploytpe diversity at fusarium head blight resistance QTLs in wheat. Theor Appl Genet. 109: 261-271.

McGrath KC (2005) Repressor- and activator-type ethylene response factors functioning in jasmonate signaling and disease resistance identified via a genome-wide screen of Arabidopsis transcription factor gene expression. Plant Physiol.139: 949-959.

Mohanty HK, Mallik S, Grover A (2000) Prospects of improving flooding tolerance in lowland rice varieties by conventional breeding and genetic engineering. Curr Sci. 78 (2): 132-137.
Phillips PC (1998) The language of gene interaction. Genetics. 149: 1167-1171.

Pungliya MS (2001) Single nucleotide polymorphism analysis in application to fine gene mapping. A Thesis submitted to the Faculty of the Worcester Polytechnic Institute for the Degree of Master of Science.

$\mathrm{Qu} \mathrm{Y,} \mathrm{Xu} \mathrm{S} \mathrm{(2006)} \mathrm{Trait} \mathrm{associated} \mathrm{microarray} \mathrm{gene}$ expression data analysis. Mol Biol Evol. 23(8):1558-1573.

Rafalski A (2002) Applications of single nucleotide polymorphisms in crop genetics. Curr Opin Plant Biol. 5: 94-100.

Rizhsky L, Liang H, Shuman J, Shulaev V, Davletova S and Mittler R (2004) When defense pathways collide: The response of Arabidopsis to a combination of drought and heat stress. Plant Physiol. 134: 1683-1696.

Rosenwald A, Wright G, Wiestner A, Chan WC, Connors JM, Campo E, Gascoyne RD, Grogan TM, MullerHermelin HK (2003) The proliferation gene expression signature is a quantitative integrator of oncogenic events that predicts survival in mantle cell lymphoma. Cancer Cell.3: 185-197.

Sardana S (1997) Submergence tolerance and elongation ability in newly developed lines of rice for Tripura. Ind J Hill Farming. 10 (1-2): 111-112.

Sarkar RK, Bhattacharjee B (2012) Rice genotype with SUB1 QTL differ in submergence tolerance, elongation ability during submergence and re-generation growth at reemergence. Rice 5:7.

Sasaki RZ, Zhao C, Zhao ZC (2000a) Submergence tolerance of transplanted rice seedlings with several plant ages in leaf number - relationship between the growth during submergence and survival. Jap J Crop Sci. 69(3): 372-379; 18.

Sasaki RZ, Zhao C, Zhao ZC (2000b) Submergence tolerance of transplanted rice seedlings with several plant ages in leaf number - duration of submergence and the role of endosperm reserves. Jap J Crop Sci.69(3): 365-371; 27.

Schadt EE, Monks SA, Drake TA, Lusis AJ, Che N, Colinayo V, Ruff TG, Milligan SB, Lamb JR, Cavet G, Linsley PS, Mao M, Stoughton RB, Friend SH (2003) Genetics of gene expression surveyed in maize, mouse and man. Nature. 422: 297-302.

Schmittgen TD, Livak KJ (2008) Analyzing real-time PCR data by the comparative CT method. Nat Protocol. 3: 11011108 .

Schramm F, Ganguli A, Kiehlmann E, Englich G, Walch D, Koskull-Doring P (2006) The heat stress transcription factor HsfA2 serves as a regulatory amplifier of a subset of genes in the heat stress response in Arabidopsis. Plant Mol Biol. 60: 759-772.

Septiningsih EM, Hidayatun N, Sanchez DL, Nugraha Y, Carandang J, Pamplona AM, Collard BYC, Ismail AM, Mackill DJ (2015) Accelerating the development of new submergence tolerant rice varieties: the case of CiherangSub1 and PSB Rc18-Sub1. Euphytica 202: 259-268.

Septiningsih EM, Ignacio JCI, Sendon PMD, Sanchez DL, Ismail AM, Mackill DJ (2013) QTL mapping and confirmation for tolerance of anaerobic conditions during germination derived from the rice landrace Ma-Zhan Red. Theor Appl Genet. 126: 1357-1366.

Septiningsih EM, Pamplona AM, Sanchez DL, Neeraja CN, Vergara GV, Heuer S, Ismail AM, Mackill DJ (2009) Development of submergence tolerant rice cultivars: the Sub1 locus and beyond. Ann Bot. 103: 151-160.

Singh S, Mackill DJ, Ismail AM (2014) Physiological basis of tolerance to complete submergence in rice involves 
genetic factors in addition to the SUB1 gene. AoB Plants. 6 , plu060.

Singh US, Dar MH, Singh S, Zaidi NW, Bari MA, Mackill DJ, Collard BCY, Singh VN, Singh JP, Reddy JN, Singh RK, Ismail AM (2013) Field performance, dissemination, impact and tracking of submergence tolerant (Sub1) rice varieties in South Asia. Sabrao J Breed Genet. 45:112-131.

Singh S, Mackill DJ, Ismail AM (2009) Responses of Sub1 rice introgression lines to submergence in the field: yield and grain quality. Field Crop Res. 113: 12-23.

Stephens JC, Schneider JA, Tanguay DA, Choi J, Acharya T, Stanley SE, Jiang R, Messer CJ, Chew A, Han JH (2001) Haplotype variation and linkage disequilibrium in 313 human genes. Sci. 293: 489-493.

Storey JD, Akey JM, Kruglyak L (2005) Multiple locus linkage analysis of genome wide expression in yeast. PLoS Biol.3: 1380-1390.

Vergara GV, Nugraha Y, Esguerra MQ, Mackill DJ, Ismail AM (2014) Variation in tolerance of rice to long-term stagnant flooding that submerges most of the shoot will aid in breeding tolerant cultivars. AoB Plants. 6: plu055; doi:10.1093/aobpla/plu055.

Wilson AC, Maxson LR and Sarich VM (1974) Two types of molecular evolution: evidence from studies of interspecific hybridization. Proc Natl Acad Sci.71:2843-2847.
Wray GA, Hahn MW, Abouheif E, Balhoff JP, Pizer M, Rockman MV, Romano LA (2003) The evolution of transcriptional regulation in eukaryotes. Mol Biol Evol. 20:1377-1419.

Wu P, Liao CY, Hu B, Yi BB, Jin WZ (2000) QTLs and epistasis for trait loci in tomato. Genetics. 143: 1807-1817.

Xu K, Xu X, Fukao T, Canlas P, Maghirang-Rodriguez R, Heuer S, Ismail AM, Bailey-Serres J, Ronald PC, Mackill DJ (2006) SublA is an ethylene-response-factor-like gene that confers submergence tolerance to rice. Nature. 442: $705-708$.

Xu X (2005) Data mining techniques in gene expression data analysis. Ph.D thesis.

Yamada N (1959) Physiological basis of resistance of rice plant against overhead flooding. Bull the Natl Inst Agric Sci., Series D (Plant Physiology, Genetics and Crops in General. 8: 1-112.

Yap YL, Zhang XW, Ling MT, Wang XH, Wongand YC, Danchin A (2004) Classification between normal and tumor tissues based on the pair-wise gene expression ratio. BMC Cancer. 4: 72doi:10.1186/1471-2407-4-72. 